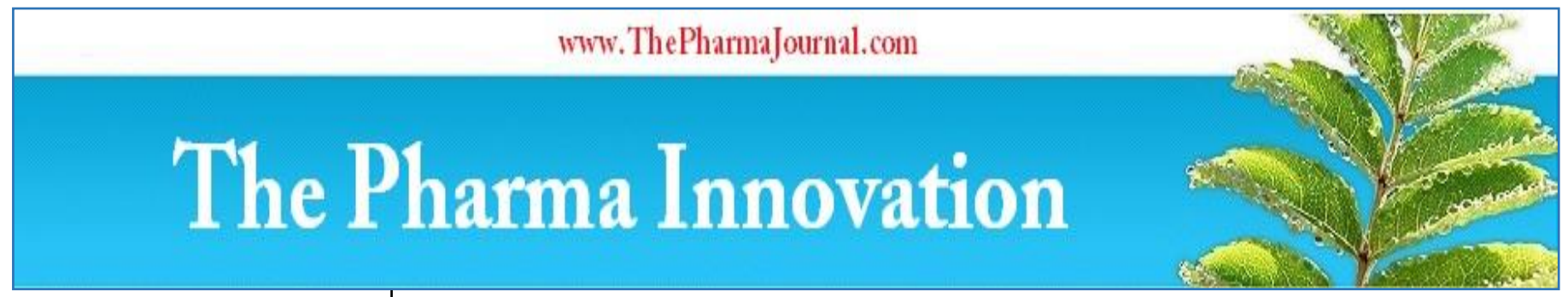

ISSN (E): $2277-7695$

ISSN (P): 2349-8242

NAAS Rating: $\mathbf{5 . 0 3}$

TPI 2018; 7(10): 22-24

(C) 2018 TPI

www.thepharmajournal.com

Received: 20-08-2018

Accepted: 21-09-2018

\section{Mandava Hemalatha}

Human Development and

Family Studies, College of Home

science, Professor Jayashakar

Telangana State Agricultural

University, Hyderabad,

Telangana, India

\section{Dr. Nasreen Banu}

Human Development and

Family Studies, College of Home

science, Professor Jayashakar

Telangana State Agricultural

University, Hyderabad,

Telangana, India

\section{Dr. P Sreedevi}

Professor, Human Development and Family Studies, College of

Home Science, Jayashakar

Telangana State Agricultural

University, Hyderabad,

Telangana, India

\section{Impact of self-efficacy on resilience of caregivers attending to Alzheimer's patients}

\author{
Mandava Hemalatha, Dr. Nasreen Banu and Dr. P Sreedevi
}

\section{DOI: https://doi.org/10.22271/tpi.2018.v7.i10a.06}

\section{Abstract}

A diagnosis of Alzheimer's disease can be a heart-wrenching experience for both the person diagnosed and the caregiver. Trying to convince the person with $\mathrm{AD}$ was a challenge and frustrating for the caregiver. The present study was conducted in twin cities of Hyderabad and Secunderabad by using Expost facto research design. Total 60 caregivers and 60patients were selected by purposive sampling method. The Connor-Davidson Resilience Scale (CD-RISC) was used for the present study which was developed by Kathryn M. Connor and Jonathan R.T. Davidson as a means of assessing resilience and self-prepared self-efficacy checklist was used to assess self-efficacy of caregivers. Results revealed that there was a significant impact of self-efficacy on resilience of caregivers attending to Alzheimer's patients.

Keywords: Alzheimer's, caregivers, self-efficacy, resilience

\section{Introduction}

Dementia was a broad category of brain diseases that cause a long-term and often gradual decrease in the ability to think and remember that is great enough to affect a person's daily functioning. The most common type of dementia was Alzheimer disease, which makes up 50\% to $70 \%$ of cases. Other common types include vascular dementia (25\%), Lewy body dementia (15\%), and front temporal dementia. The terms "Alzheimer" and "dementia" were often used interchangeably, but the conditions were not the same. "Dementia" was a term that means a person is no longer able to function on their own because of a lasting impairment of multiple mental abilities affecting memory, attention, and reasoning. AD was an irreversible, progressive brain disorder that slowly destroys memory and thinking skills, and eventually the ability to carry out the simplest tasks. In most people with Alzheimer, symptoms first appear in their mid-60s. Estimates vary, but experts suggest that more than 5 million Americans may have Alzheimer. NIA (National Institute on Aging, 2017) ${ }^{[1]}$. As populations age, due to increasing life expectancy, the number of people with dementia was increasing. WAR (World Alzheimer's Report, 2016) ${ }^{[2]}$. Estimated that there were 46.8 million people worldwide living with dementia in 2015) ${ }^{[10]}$. And this number will reach 131.5 million in 2050. A caregiver was an unpaid or paid member of a person's social network who helps them with activities of daily living. Care giving was most commonly used to address impairments related to old age, disability, a disease, or a mental disorder. Typical duties of a caregiver might include taking care of someone who has a chronic illness or disease; managing medications or talking to doctors and nurses on someone's behalf; helping to bathe or dress someone who is frail or disabled; or taking care of household chores, meals, or bills for someone who cannot do these things alone. A diagnosis of $\mathrm{AD}$ can be a heart-wrenching experience for both the person diagnosed and the caregiver. The person with AD may not remember or may not admit to having the disease or ever being told they had Alzheimer. Trying to convince them otherwise was fruitless and frustrating for the caregiver. The caregiver need to get appropriate emotional support. Depression was common in caregivers of people with AD. As the disease progresses, it will be harder for the person with AD to fulfil the family roles they have typically played in the family. For example, if he or she was the only driver in the family, it will be important for family members to find alternative means of transportation (e.g., learning how to drive, recruiting volunteer drivers from among family and friends, using public transportation or para-transit). Resilience was the process of adapting well in the face of adversity, trauma,

\section{Mandava Hemalatha}

Human Development and Family Studies, College of Home science, Professor Jayashakar Telangana State Agricultural University, Hyderabad,

Telangana, India 
tragedy, threats or significant sources of stress such as family and relationship problems, serious health problems or workplace and financial stressors. It means "bouncing back" from difficult experiences. Caregiver self-efficacy was conceptualized as individual's beliefs in their ability to carry out activities and tasks specific to care giving. In regard to care giving, self-efficacy theory suggests that individuals with higher levels of self-efficacy for performing tasks of care giving have greater levels of success in completing the tasks, lower levels of psychological and physical illness, reduced rates of burnout, and greater levels of well-being than those with low levels of self-efficacy. Care giving task demands and changes over time. Several dimensions have been described for caregiver self-efficacy, including self-efficacy for caregivers' self care, self-efficacy for controlling caregivers' cognitions and upsetting thoughts specific to care giving, selfefficacy for caregivers' coping, self-efficacy for managing care recipients' disruptive behaviours, and self-efficacy for managing care recipients' symptoms. As Alzheimer caregivers frequently report experiencing high levels of stress. It can be overwhelming to take care of a loved one with Alzheimer, but too much stress can be harmful to the caregiver. More than $40 \%$ of family caregivers reported that the emotional stress of their role was high or very high and very few caregivers were having resilience (Alzheimer's disease International) which shows that there was a need for conducting research study on Resilience in caregivers of Alzheimer patients. The present study was proposed to study the extent of resilience in Alzheimer disease caregivers and their ability to withstand adversity and this study seeks to identify whether self-efficacy had its impact on resilience of the caregiver or not. For tinsky et al. (2002) ${ }^{[5]}$. claimed that higher levels of self efficacy were strongly associated with lower levels of caregiver depressive symptoms. It was also found that a negative association was found between selfefficacy and caregivers' physical health symptoms i.e., higher service use self-efficacy scores $(b=-0.20, p<0.01)$ and higher symptom management self-efficacy scores $(b=-0.16$, $p<0.05)$ were associated with fewer physical health symptoms. Rabinowitz et al. (2016) ${ }^{[6]}$. studied Self-efficacy as a moderator of the relationship between care recipient memory and behavioural problems and caregiver depression in female dementia caregivers. Results revealed that selfefficacy for managing disruptive behaviours and self efficacy for controlling upsetting thoughts had a direct effect on depression. Results of these analyses indicated that for low levels of caregiver self efficacy and managing disruptive behaviours, the relationship between care recipient memory, behaviour Problem and caregiver depressive symptoms was significant $(\mathrm{t}=3.50$, df $=243, \mathrm{P}=0.001)$. Dwyer et al $(2013)^{[11]}$. investigated in a pilot study on Suicidal ideation and resilience in family caregivers of people with dementia. Three themes were identified in the data - 'experiences of suicidal ideation', 'risk factors' and 'resilience'. Four of the nine participants had experienced suicidal thoughts and two had made preparations for a suicidal act. Risk factors included pre-existing mental health problems, physical health conditions, and conflict with other family or care staff. Factors positively associated with resilience included the use of positive coping strategies, faith, social support and personal characteristics.

\section{Materials and Methods}

The present study was conducted in twin cities of Hyderabad and Secunderabad by using Ex-post facto research design were selected for collecting data. Total 60 caregivers and 60 patients were selected by purposive sampling method. The data from the respondents was collected by both standardized and self-constructed interview schedule, which includes the measurement of variables under investigation. Self- efficacy scale was developed after going through many reviews. The scale consists of total 10 items which were arranged on a four point rating scale of Not at all true (1) to very much true (4). The Connor-Davidson Resilience Scale (CD-RISC) was used for the present study which was developed by Kathryn M. Connor and Jonathan R.T. Davidson as a means of assessing resilience. The scale comprises of 25 items, each rated on a 5point scale: Not at all true (1), rarely true (2), sometimes true (3), often true (4), very much true (5) with higher scores reflecting greater resilience. Regression analysis was used to know the impact of self-efficacy on resilience of caregivers attending to Alzheimer's patients.

\section{Results and Discussion}

Table 1: Self efficacy of the caregivers attending to Alzheimer patientsN $=60$

\begin{tabular}{|c|c|c|c|c|c|c|c|c|}
\hline \multirow{2}{*}{ S. No } & \multirow{2}{*}{ Area } & \multirow{2}{*}{ Category } & \multicolumn{2}{|c|}{ Males } & \multicolumn{2}{|c|}{ Females } & \multicolumn{2}{c|}{ Total } \\
\cline { 3 - 9 } & & F & \% & F & \% & F & \% \\
\hline \multirow{3}{*}{1} & \multirow{2}{*}{ Self efficacy -Total } & Low & 3 & 18 & 0 & 0 & 3 & 5 \\
\cline { 3 - 9 } & & Average & 3 & 18 & 8 & 19 & 11 & 18 \\
\cline { 3 - 9 } & & High & 11 & 65 & 35 & 81 & 46 & 77 \\
\hline
\end{tabular}

It was found from the above table (4.3.3) that more than three fourth of the $(77 \%)$ caregivers were having high self efficacy, $(18 \%)$ were having moderate and only $(5 \%)$ were having low self -efficacy. found that self-efficacy accounted for a significant percentage of the variance in positive aspects of care giving after controlling for other factors commonly associated with positive aspects of care giving including caregiver demographics, care recipient neuropsychiatric symptoms, and caregiver depression and finally concluded that high self-efficacy relates to caregiver's perception of positive aspects of the care giving experience.

$\mathrm{Au}$ et al. (2009) ${ }^{[9]}$. Claimed that self-efficacy acted as a partial mediator between social support and depressive symptoms of these caregivers. Findings suggested that selfefficacy may function as a mechanism through which social support influences depressive symptoms, and the importance of this self-efficacy mechanism can be domain-specific.

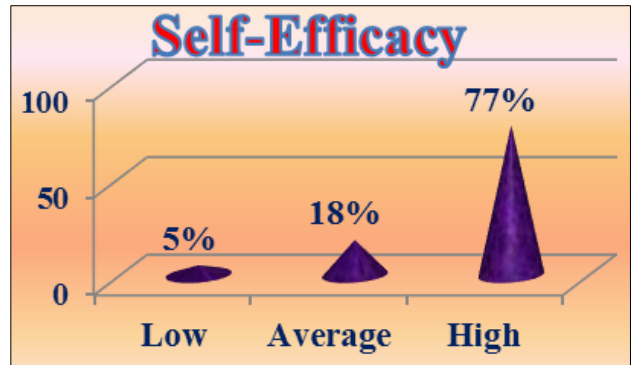

Fig 1: Self efficacy of the caregivers attending to Alzheimer patients

Table 2: Resilience of the caregivers attending to Alzheimer patients $\mathrm{N}=60$

\begin{tabular}{|c|l|c|c|c|c|c|c|c|}
\hline \multirow{2}{*}{ S. No } & \multirow{2}{*}{ Area } & \multirow{2}{*}{ Category } & \multicolumn{2}{|c|}{ Males } & \multicolumn{2}{|c|}{ Females } & \multicolumn{2}{|c|}{ Total } \\
\cline { 3 - 9 } & & F & \% & F & \% & F & \% \\
\hline \multirow{2}{*}{1} & \multirow{3}{*}{ Resilience } & Low & 3 & 17 & 3 & 7 & 6 & 10 \\
\cline { 3 - 9 } & & Average & 7 & 41 & 22 & 51 & 29 & 48 \\
\cline { 3 - 9 } & & High & 7 & 41 & 18 & 42 & 25 & 41 \\
\hline
\end{tabular}


It was found from the above table that $48 \%$ of caregivers reported that they were having moderate resilience, $41 \%$ of caregivers were having high resilience, and $10 \%$ of the caregivers were having low resilience.

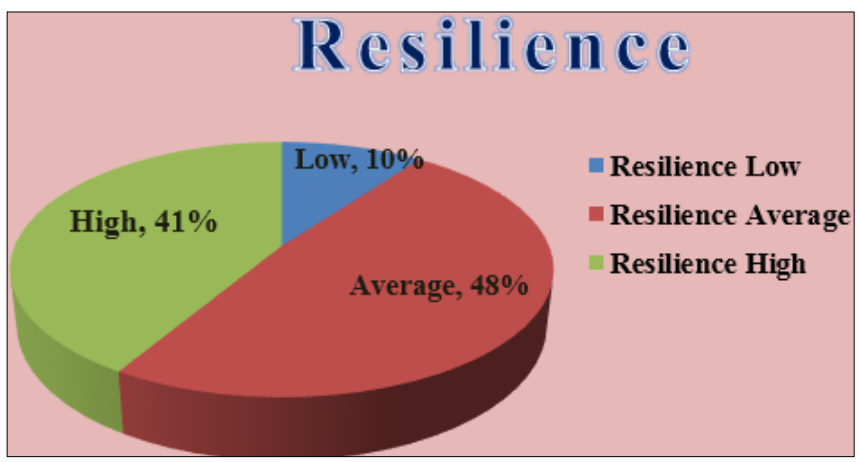

Fig 2: Resilience of the caregivers attending to Alzheimer patients

Table 3: Model Summary of independent variable self efficacy and dependent variable resilience of the caregiver

\begin{tabular}{|c|c|c|c|c|}
\hline Model & $\mathbf{R}$ & $\begin{array}{c}\mathbf{R} \\
\text { Square }\end{array}$ & $\begin{array}{c}\text { Adjusted R } \\
\text { Square }\end{array}$ & $\begin{array}{c}\text { Std. Error of } \\
\text { the Estimate }\end{array}$ \\
\hline 1 & .398 & .158 & .113 & 17.68918 \\
\hline
\end{tabular}

A Predictors: Self efficacy

In the above model $\mathrm{R}$ denotes the correlation between independent and dependent variable. $\mathrm{R}=0.398$. Since this shows there was no correlation between independent variable of caregivers i.e., self-efficacy $\mathrm{R}$ square indicates the proportion of variance in promoting resilience of the caregiver. Here the $\mathrm{R}^{2}=0.158$ which means that independent variable was having only $15.8 \%$ influence on dependent variable resilience of the caregiver.

Table 4: ANOVA of independent variables self efficacy and dependent variable resilience of the caregiver

\begin{tabular}{|c|c|c|c|c|c|}
\hline & Sum of Squares & Df & Mean Square & F & Sig. \\
\hline Regression & 3289.600 & 3 & 1096.533 & 3.504 & .021 \\
\hline Residual & 17522.800 & 56 & 312.907 & & \\
\hline Total & 20812.400 & 59 & & & \\
\hline
\end{tabular}

A Predictors: Self efficacy

B Dependent Variable: Resilience

It was evident from the above table that there was a significant impact of self efficacy on dependent variable of resilience of the caregiver as $\mathrm{p}=0.021$ which was less than 0.05

Table 5: Coefficients of independent variable self efficacy and dependent variable resilience of the caregive

\begin{tabular}{|c|c|c|c|c|c|c|}
\hline \multirow{2}{*}{$\begin{array}{l}\text { S. } \\
\text { No }\end{array}$} & \multirow{2}{*}{$\begin{array}{c}\text { Independent } \\
\text { variables }\end{array}$} & \multicolumn{2}{|c|}{\begin{tabular}{|c|}
$\begin{array}{c}\text { Unstandardized } \\
\text { Coefficients }\end{array}$ \\
\end{tabular}} & \multirow{2}{*}{\begin{tabular}{|c|}
$\begin{array}{c}\text { Standardized } \\
\text { Coefficients }\end{array}$ \\
Beta \\
\end{tabular}} & \multirow[t]{2}{*}{$\mathbf{T}$} & \multirow[t]{2}{*}{ Sig. } \\
\hline & & B & & & & \\
\hline 1 1.. & Self efficacy & 1.054 & .365 & .356 & 2.88 & 5.006 \\
\hline
\end{tabular}

The above table provides the impact of independent variable i.e., self- efficacy on resilience of caregivers. For Self efficacy the $t$ value was 2.885 and $p$ value was 0.006 which was less than 0.01 and hence it can be inferred that selfefficacy was having significant impact on resilience of the caregiver. For a single unit increase of self efficacy will increase dependent variable resilience of the caregiver increases by 1.054 . The findings of present study showed that self efficacy had its impact on resilience of the caregiver. According to Lansac et $a^{l}$. (2012) ${ }^{[10]}$, high resilience scores were significantly correlated to self-efficacy. Higher resilience relates to a good emotional and physical status in caregivers. Guccione (2014) ${ }^{[11]}$, found resilient individuals exhibiting higher levels of self-efficacy and claimed that selfefficacy was a cognitive appraisal that concerns people's beliefs in their own capabilities to exercise control over their own functioning and over events that affect their lives as they appraise their resources to respond to stressor.

\section{Conclusion}

Finally it can be concluded from the present study that believing in one's own capabilities can increase resilience of the person. Regular consultation and supportive care in the form of counseling was very much required at the hospitals for caregivers to become more resilient.

\section{References}

1. National Institute on Aging, Basics of Alzheimer disease and dementia. https://www.nia.nih.gov/health/whatalzheimers-disease. National Institute on Aging. [Accessed 25 June 2017]

2. Prince PM, Herrera AC, Knapp $M$, Guerchet $M$, Karagiannidou M, World Alzheimer Report Improving healthcare for people living with dementia. Alzheimer Disease International 501:3. https:// www. alz. co. uk/global-solutions [Accessed 21 September 2016]

3. Bandura A, Adams NE. Analysis of self-efficacy theory of behavioral change. Cognitive Therapy \& Research, 1977, 1: 287-308. https:// www. uky. edu/ eushe2/Bandura/Bandura1977CTR-Adams.pdf

4. Alzheimer's disease International. https:// www. alz.c o.uk /research/st atistics [Accessed 21 May 2015]

5. Fortinsky RH, Kercher K, Burant CJ. Measurement and correlates of family caregiver self-efficacy for managing dementia, Aging \& Mental Health. 2002; 6:153-160.

6. Rabinowitz YG, Mausbach BT, Gallagher-Thompson D. Self-efficacy as a moderator of the relationship between care recipient memory and behavioral problems and caregiver depression in female dementia caregivers. Alzheimer's disease Association Disorders. 2009; 23:389-39.

7. Dwyer S, Moyle W, Wyk S. Suicidal ideation and resilience in family carers of people with dementia: A ilot qualitative study. Aging \& Mental Health. 2013, 17:753760 .

8. Semiatin AM, Connor MK. The relationship between self-efficacy and positive aspects of caregiving in Alzheimer disease caregivers. Aging \& Mental Health, 2016, 683-8.

9. Au A, Lai MK, Lau KM, Pan PC, Lam L, Thompson L, Gallagher-Thompson D. Social support and well-being in dementia family caregivers: the mediating role of selfefficacy, Aging \& Mental Health. 2009; 13:761-8. doi: 10.1080/13607860902918223

10. Lansac V, Crespo Lopez M, Caceres R, Rodriguez-Poyo $\mathrm{M}$, Resilience in caregivers of patients with dementia: A preliminary study. 2012; 47:102-9.

11. Guccione AA. Resilience and Self-effi cacy As Mediators of Quality of Life in Geriatric Rehabilitation. 2014; 30: 164-169. https://www.nursingcenter. com/ journalarticle? Article_ID $=2535346 \&$ Journal_ID $=515682 \&$ Issue_ID $=25$ 35322, DOI:10.1016/j.regg.2011.11.004 